A.L. Lazaar ${ }^{1}$, B.E. Miller ${ }^{1}$, G. Francombe ${ }^{2}$, A. Duvoix ${ }^{3}$, S.A. Natanek ${ }^{4}$ and M.I. Polkey ${ }^{4}$

${ }^{1}$ Clinical Discovery, Respiratory Therapy Area, GlaxoSmithKline, King of Prussia, PA, USA. ${ }^{2}$ Clinical Statistics Respiratory, GlaxoSmithKline, Uxbridge, ${ }^{3}$ Dept of Medicine, University of Cambridge, Cambridge Institute for Medical Research, Wellcome Trust/MRC Building, Cambridge, and ${ }^{4}$ NIHR Respiratory Biomedical Research Unit, Royal Brompton Hospital, Imperial College, London, UK.

Correspondence: M.I. Polkey, Dept of Respiratory Medicine, Royal Brompton Hospital, Fulham Road, London, SW3 6NP, UK. E-mail: m.polkey@rbht.nhs.uk

Received: Feb 262013 | Accepted: April 252013

Support statement: The contribution to this work from S.A. Natanek and M.I. Polkey was supported by NIHR Respiratory Biomedical Research Unit at the Royal Brompton Hospital and Imperial College, London, who part fund M.I. Polkey's salary. S.A. Natanek (nee Sathyapala) was a recipient of a Wellcome Trust award (079686). ECLIPSE was wholly funded by GSK.

Conflict of interest: Disclosures can be found alongside the online version of this article at www.erj.ersjournals.com

\title{
References
}

Troosters T, Gosselink R, Decramer M. Short- and long-term effects of outpatient rehabilitation in patients with chronic obstructive pulmonary disease: a randomized trial. Am J Med 2000; 109: 207-212.

2 Seymour JM, Moore L, Jolley CJ, et al. Outpatient pulmonary rehabilitation following acute exacerbations of COPD. Thorax 2010; 65: 423-428.

Shrikrishna D, Patel M, Tanner RJ, et al. Quadriceps wasting and physical inactivity in patients with COPD. Eur Respir J 2012; 40: 1115-1122.

4 Seymour JM, Spruit MA, Hopkinson NS, et al. The prevalence of quadriceps weakness in COPD and the relationship with disease severity. Eur Respir J 2010; 36: 81-88.

Steiner MC, Roubenoff R, Tal-Singer R, et al. Prospects for the development of effective pharmacotherapy targeted at the skeletal muscles in chronic obstructive pulmonary disease: a translational review. Thorax 2012; 67: 1102-1109.

6 Dogra C, Changotra H, Wedhas N, et al. TNF-related weak inducer of apoptosis (TWEAK) is a potent skeletal muscle-wasting cytokine. FASEB J 2007; 21: 1857-1869.

7 Ju C, Chen R. Skeletal muscle dysfunction and the related mechanism in chronic obstructive pulmonary disease. Eur Respir J 2009; 34: Suppl. 53, 604s.

8 Carrero JJ, Ortiz A, Qureshi AR, et al. Additive effects of soluble TWEAK and inflammation on mortality in hemodialysis patients. Clin J Am Soc Nephrol 2009; 4: 110-118.

9 Remels AH, Gosker HR, Schrauwen P, et al. TNF-alpha impairs regulation of muscle oxidative phenotype: implications for cachexia? FASEB J 2010; 24: 5052-5062.

10 Vestbo J, Anderson W, Coxson HO, et al. Evaluation of COPD Longitudinally to Identify Predictive Surrogate Endpoints (ECLIPSE). Eur Respir J 2008; 31: 869-873.

11 Waschki B, Spruit MA, Watz H, et al. Physical activity monitoring in COPD: compliance and associations with clinical characteristics in a multicenter study. Respir Med 2012; 106: 522-530.

12 Natanek SA, Gosker HR, Slot IG, et al. Heterogeneity of quadriceps biopsy phenotype in chronic obstructive disease (COPD); implications for stratified medicine? Muscle Nerve 2013 [In press DOI: 10.1002/mus.23784].

\section{Genome-wide genetic ancestry measurements to predict lung function in European populations}

To the Editor:

A number of models have been proposed to predict spirometric lung function using age, sex, height and self-reported ethnicity $[1,2]$. These models are particularly important to derive per cent predicted lung function and establish the severity of lung diseases such as chronic obstructive pulmonary disease (COPD) [3]. Compared to self-reported race and/or ethnicity, genetic data can provide more accurate and objective measurements of ancestry and has the potential to alleviate some of the problems related to the lack of consensus on the definition of race and ethnicity worldwide [4]. A recent report suggested that genetically determined ancestry improves predicted lung-function measurements in African Americans [5]. Here, we 
test whether genetic ancestry derived from genome-wide genotyping data is useful to predict lung function in a diverse European population.

The population used in this study is part of a lung expression quantitative trait loci (eQTL) mapping study $[6,7]$. Briefly, research participants were recruited from three academic sites: Laval University (Québec, QC, Canada), University of British Columbia (Vancouver, BC, Canada), and Groningen University (Groningen, the Netherlands), henceforth referred to as Laval, UBC, and Groningen, respectively. All subjects were genotyped for $\sim 1.2$ million single nucleotide polymorphisms (SNPs) using the Illumina Human1M-Duo BeadChip (Illumina, Inc., San Diego, CA, USA). Subjects from Laval and UBC provided written informed consent and the study was approved by the ethics committees of the respective study sites. At Groningen, the study protocol was consistent with the research code of the University Medical Center Groningen and Dutch national ethical and professional guidelines ("Code of conduct; Dutch federation of biomedical scientific societies"; http://www.federa.org). Prior to the analysis, standard genotyping quality controls and exclusion of patients with disorders that affected lung function (other than COPD) were applied. After these filters, the Laval cohort consisted of 399 French Canadian subjects with a mean age of $63.6 \pm 9.8$ years. The mean pre-bronchodilator forced expiratory volume in $1 \mathrm{~s}(\mathrm{FEV} 1)$ for males $(n=222)$ and females $(n=177)$ were $2.44 \pm 0.73$ and $1.88 \pm 0.56 \mathrm{~L}$, respectively. $56.3 \%$ of the Laval samples were diagnosed with COPD based on Global Initiative for Chronic Obstructive Lung Disease recommendations [3]. The Groningen cohort included 99 subjects with a mean age of $61.5 \pm 9.8$ years. $61.6 \%$ of the Groningen subjects were males. The mean pre-bronchodilator FEV1 was $2.42 \pm 0.87 \mathrm{~L}$ for males $(\mathrm{n}=61)$ and $1.96 \pm 0.83 \mathrm{~L}$ for females $(n=38) .58$ subjects $(58.6 \%)$ were diagnosed with COPD. Finally, the UBC cohort was composed of 260 subjects with a mean age of $63.7 \pm 9.8$ years including a similar proportion of males $(52.7 \%)$ and females. The mean pre-bronchodilator FEV1 was $2.61 \pm 0.78 \mathrm{~L}$ for males and $1.86 \pm 0.63 \mathrm{~L}$ for females. 120 subjects from UBC (46.2\%) were afflicted with COPD. The three cohorts combined and analysed in this study consisted of 758 individuals, all of European descent confirmed by genotyping.

The 758 subjects were used to calculate the genetic ancestry using the ADMIXTURE program [8]. SNPs in linkage disequilibrium $\left(\mathrm{r}^{2} \geqslant 0.1\right)$ with any other SNP within a 50-SNP sliding window were excluded, resulting in a set of 59,767 autosomal SNPs entered in the ADMIXTURE program. As performed by KUMAR et al. [5], we used genotypes from unrelated HapMap European and African populations as reference sets. HapMap reference set for Asian was also added, owing to the large proportion of this ethnic group in Vancouver. ADMIXTURE was run with three ancestral populations $(K=3)$. The mean percentage of European ancestry was very high in the Laval cohort $(97.4 \pm 0.7 \%)$. This percentage was slightly lower in Groningen and UBC (95.8 \pm 3.7 and $95.5 \pm 3.8$, respectively). Together, these cohorts gave a more heterogeneous distribution of genetic ancestry (fig. la and b).

We used linear regression, stratified by sex, to evaluate the association between lung function and European ancestry. Lung function tested includes FEV1, forced vital capacity (FVC), and FEV1/FVC ratio. The lung function values were adjusted for the study sites using linear regression. Residuals were then tested for association with the percentage of European ancestry. There was no significant association with lung function and the percentage of European ancestry (for FEV1, $\mathrm{r}^{2}=0.004$ and $\mathrm{p}=0.35$ for males; and $\mathrm{r}^{2}=0.001$ and $\mathrm{p}=0.71$ for females).

Two models were compared to assess whether genetic ancestry influences the pulmonary function predictions. The first, labelled the standard model, included only variables used by HANKINSON et al. [1] and the study site (i.e. lung function $\sim$ age + age $^{2}+$ height $^{2}+$ study site). The second, labelled ancestry-based model, included all the same variables with one additional term for individual genetic European ancestry (i.e. lung

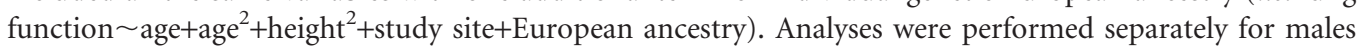
and females. Figure $1 \mathrm{c}$ shows the differences between the two models in males that range from $-277.8 \mathrm{~mL}$ to $37.7 \mathrm{~mL}$ with a mean absolute difference of $13.3 \pm 22.4 \mathrm{~mL}$. In females (fig. 1d), the differences between models range from $-13.7 \mathrm{~mL}$ to $155.8 \mathrm{~mL}$ with a mean absolute difference of $6.0 \pm 12.4 \mathrm{~mL}$. The adjusted coefficients of determination (adjusted $\mathrm{R}^{2}$ ) measuring the proportion of variance in FEV1 explained by the two models was not different (males: 0.175 for the standard model compared to 0.175 for ancestry-based model; females: 0.259 for the standard model compared to 0.261 for ancestry-based model). These results suggest that genetically determined ancestry does not influence the predicted lung function measurements in this diverse European population. We then evaluated the number of subjects whose COPD severity classification [3] changed when predicted FEV1 was obtained from a standard model compared to an ancestry-based model. For the 389 subjects having COPD, only two subjects were reclassified $(0.51 \%)$ into lower severity stages (stage 2 to stage 1 ) using the ancestry-based model.

This study does not demonstrate the utility of genome-wide genetic ancestry to predict lung function in European populations. The mean absolute differences in predicted FEV1 observed between models with or without European ancestry were smaller than those observed in African Americans [5]. The French 

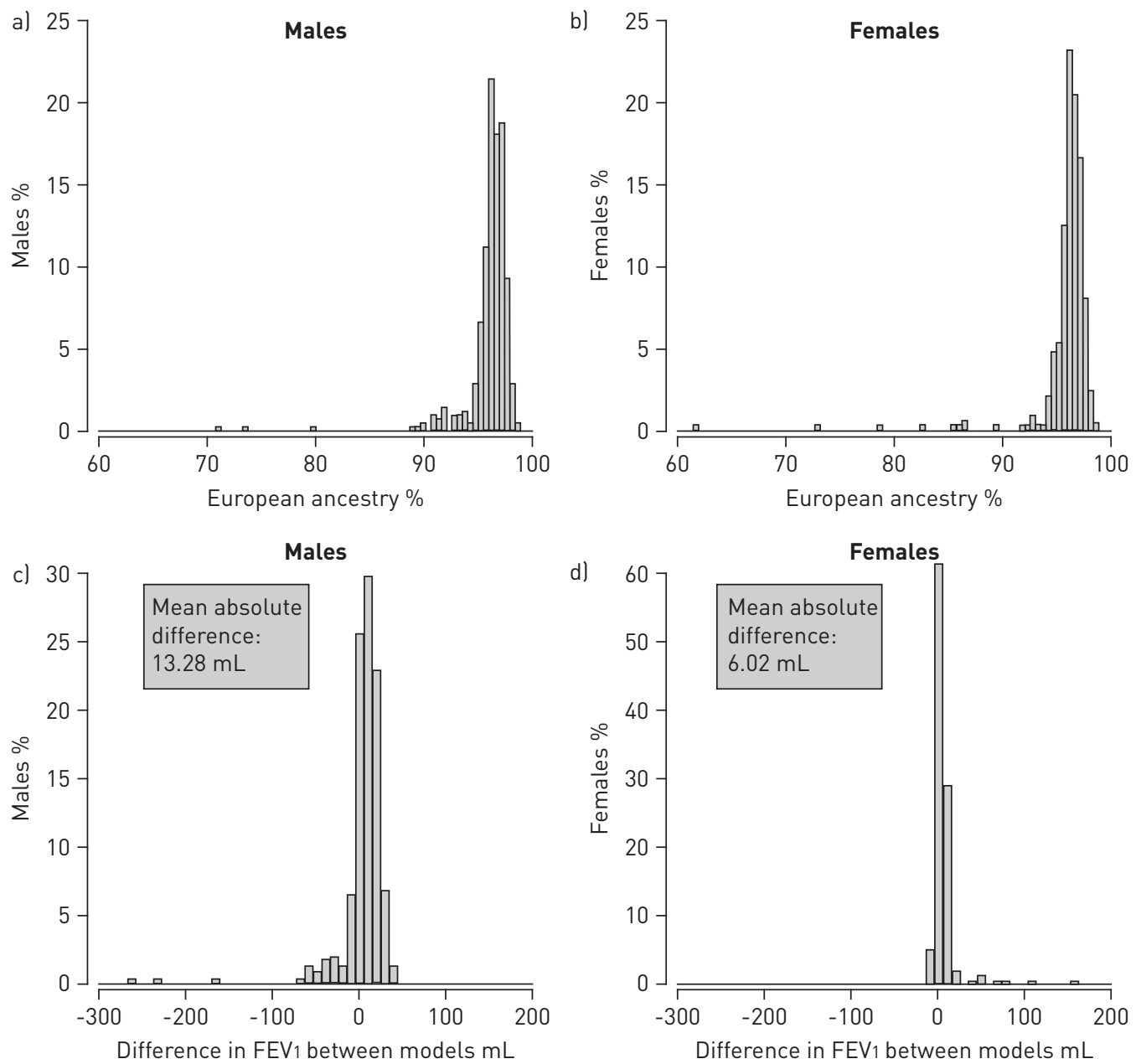

FIGURE 1 Genetically determined ancestry distribution and differences in predicted forced expiratory volume in $1 \mathrm{~s}$ (FEV1) between the standard and ancestry-based models in males and females of European origins. a) and b) show the percentage of European ancestry in males $(n=420)$ and females $(n=338)$, respectively. $c)$ and d) show the difference in predicted FEV1 between the standard model and the ancestry-based model in males and females, respectively.

Canadian population is known to have less genetic heterogeneity than most general European populations [9]. Although more variability in genetic ancestry was observed in Groningen and UBC, the influence of genetic markers on lung function prediction was still minor. The smaller range of genetic ancestry (fig. 1a and b) observed in our study may explain the lack of association between this term and both FEV1 and FVC as well as the practically null effect of the ancestry-based prediction model on classification of COPD severity.

This study was based on European patients undergoing lung surgery. Although we excluded patients with disorders that affected lung function, this population does not represent healthy individuals and the results cannot be directly extrapolated to the general population. However the results may be applicable to a large number of patients seen in respiratory units. The low variability in the percentage of European ancestry observed in this study, especially among French Canadians, suggests that measures of individual genetic ancestry based on genetic markers are unlikely to have a major impact, if any, on lung function prediction and classification of disease severity in this population. A greater role of genetics is likely to occur in Central/Southern and Western Europe populations compared to our populations living or originating from Northern European populations. Accordingly, further evaluations of genetically determined ancestry to predict lung function are warranted in healthy and more admixed European populations in order to confirm or infirm the negligible impact of genetic data to estimate lung function observed in this study. Notwithstanding, it was suggested that self-identification of race and ethnicity is inappropriate to implement recommended guidelines for spirometry [4]. Genetically determined ancestry will thus be an effective alternative to self-reported ethnicity in some populations. 
In conclusion, based on current evidence, it would be premature to integrate genome-wide genotyping data as part of routine evaluation of lung function in European populations. Whether the same genomic data can be leveraged to predict response to medications and to personalise the management of patients with respiratory diseases are currently important research areas. populations http://ow.ly/nxIai

Jean-Christophe Bérubé ${ }^{1}$, Maxime Lamontagne ${ }^{1}$, Christian Couture ${ }^{1}$, David Nickle ${ }^{2}$, Wim Timens ${ }^{3}$, Dirkje S. Postma ${ }^{4}$, Don D. Sin ${ }^{5,6}$, Peter D. Paré, ${ }^{5,6}$ Michel Laviolette ${ }^{1}$ and Yohan Bossé, , $^{1,7}$

${ }^{1}$ Institut universitaire de cardiologie et de pneumologie de Québec, Quebec, QC, ${ }^{5}$ UBC James Hogg Research Center, St. Paul's Hospital, Vancouver, BC, ${ }^{6}$ Respiratory Division, Dept of Medicine, The University of British Columbia, Vancouver, BC, and ${ }^{7}$ Dept of Molecular Medicine, Laval University, Quebec, QC, Canada. ${ }^{2}$ Merck \& Co. Inc., Rahway, NJ, USA. ${ }^{3}$ Dept of Pathology and Medical Biology, University of Groningen, University Medical Center Groningen, GRIAC Research Institute, Groningen, and ${ }^{4}$ Dept of Pulmonology, University of Groningen, University Medical Center Groningen, GRIAC Research Institute, Groningen, The Netherlands.

Correspondence: Yohan Bossé, Laval University, Institut universitaire de cardiologie et de pneumologie de Québec, Pavillon Marguerite-d'Youville, Y4190, 2725, chemin Ste-Foy, Québec, QC, G1V 4G5, Canada.

E-mail: yohan.bosse@crhl.ulaval.ca

Received: Feb 272013 | Accepted: May 122013

Support statement: This study was funded by Merck Research Laboratories. It was also partly supported by the Chaire de pneumologie de la Fondation JD Bégin de l'Université Laval, the Fondation de l'Institut universitaire de cardiologie et de pneumologie de Québec, and the Respiratory Health Network of the FRQS.

Conflict of interest: Disclosures can be found alongside the online version of this article at www.erj.ersjournals.com

Acknowledgements: The authors would like to thank Christine Racine and Sabrina Biardel at the IUCPQ site of the Respiratory Health Network Tissue Bank of the FRQS (Quebec, QC, Canada) for their valuable assistance. Y. Bossé is a research scholar from the Heart and Stroke Foundation of Canada. D.S. Postma is the holder of a KNAW (Royal Academy of Arts and Sciences) chair for research. D.D. Sin holds a Canadian Research Chair in COPD. P.D. Pare is a Michael Smith Foundation Distinguished Scholar and the Jacob Churg Distinguished Researcher.

\section{References}

1 Hankinson JL, Odencrantz JR, Fedan KB. Spirometric reference values from sample of the general U.S. Population. Am J Respir Crit Care Med 1999; 159: 179-187.

2 Pellegrino R, Viegi G, Brusasco V, et al. Interpretative strategies for lung function tests. Eur Respir J 2005; 26: 948-968.

3 Rabe KF, Hurd S, Anzueto A, et al. Global strategy for the diagnosis, management, and prevention of chronic obstructive pulmonary disease: GOLD executive summary. Am J Respir Crit Care Med 2007; 176: 532-555.

4 Braun L, Wolfgang M, Dickersin K. Defining race/ethnicity and explaining difference in research studies on lung function. Eur Respir J 2013; 41: 1362-1370.

5 Kumar R, Seibold M a, Aldrich MC, et al. Genetic ancestry in lung-function predictions. N Engl J Med 2010; 363: 321-330.

6 Bossé Y, Sin D, Laviolette M, et al. Hypothesis-driven Research on Genomic Data Derived from a Large Scale Lung EQTL Mapping Study. WebmedCentral LUNG 2010; 1: WMC00724.

7 Hao K, Bossé Y, Nickle DC, Paré PD, et al. Lung eQTLs to help reveal the molecular underpinnings of asthma. PLoS genetics 2012; 8: e1003029.

8 Alexander DH, Novembre J, Lange K. Fast model-based estimation of ancestry in unrelated individuals. Genome Res 2009; 19: 1655-1664.

9 Scriver CR. Human genetics: lessons from Quebec populations. Annu Rev Genomics Hum Genet 2001; 2: 69-101. 